Bangladesh Journal of Neuroscience 2015; Vol. 31 (2): 65-69

\title{
Serum Lead Level and Polyneuropathy among Bangladeshi Patients
}

\author{
SWAPON KUMAR GHOSE ${ }^{1}$, KAZI GIAS UDDIN AHMED ${ }^{1}$, AHMED HOSSIAN CHOWDHURY², \\ A T M HASIBUL HASAN ${ }^{3}$, KANOL SAHA ${ }^{2}$, HASHMI SINA ${ }^{2}$, MD. ARIFUZZAMAN ${ }^{2}$, \\ IFTIKHER ALAM ${ }^{4}$, AMIT WAZIB $^{4}$, ASM REZAUL KARIM ${ }^{5}$, MD. RAFIQUL ISLAM ${ }^{6}$, \\ MANSUR HABIB ${ }^{7}$, QUAZI DEEN MOHAMMAD ${ }^{8}$
}

\begin{abstract}
:
Background: Heavy metals may produce various symptoms among the exposed, of which polyneuropathy is a matter of real concern. Our aim was to determine the pattern and association between polyneuropathy and blood lead level.Methods: This case control study was done in the department of Neurology, Bangabandhu Sheikh Mujib Medical University, Dhaka in collaboration with Bangladesh Atomic Energy Centre from July 2001 to June 2002. The lead concentration in the blood was detected by Xray fluorescence (XRF) technique. Nerve conduction study and CSF examination were done among the cases. Result: Data were collected from 92 respondents, of whom cases and controls were equal in number with a male to female ratio of 8.17:1. Mean age of the cases and controls were $30.87+14.53$ years and $30.91+12.03$ years respectively. Among the cases, 55\% had sub acute type of polyneuropathy, followed by acute and chronic type of polyneuropathy among $30 \%$ and $15 \%$ respondants respectively. The mean CSF protein level was $112.00+65.04 \mathrm{gm} / \mathrm{L}$. The mean CSF protein was higher in acute polyneuropathy than in subacute and chronic cases $(p<.001)$. The mean blood lead level among cases was 45.5587 with a standard deviation (SD) of +35.2625 and among control were 33.2065 with a $S D$ of +5.6793 . The difference was statistically significant $(p=0.021)$.
\end{abstract}

Conclusion: Increase blood level of lead is associated with polyneuropathy.

Key words: Polyneuropathy, lead concentration in blood.

Introduction:

With industrialization and a tendency to keep a higher growth rate Bangladesh is driving towards becoming a middle income country. As a consequence of industrial revolution the chances of environmental and occupational exposure to these toxins are increasing. Toxicity from environmental exposure to lead has long term consequences. The non-biodegradable nature of lead poses a persistent threat for public health. Exposure to lead leads to breakdown of cellular homeostasis with a major effect on central and peripheral nervous system ${ }^{1}$. The usual form of lead neuropathy consists of motor weakness that primarily involves the wrist and finger extensors, especially among the painters but later spreads to other muscles with only minimal sensory involvement. Infrequently, there is a more typical toxic neuropathy with predominant distal sensory and motor involvement. The motor neuropathy is more likely to develop following relatively short-term exposure to high lead concentrations and evolves in a sub acute fashion ${ }^{2-4}$.

1. Associate Professor of Neurology, Dhaka Medical College Hospital

2. Assistant Professor of Neurology, Dhaka Medical College Hospital

3. Registrar (Neurology),Dhaka Medical College Hospital

4. Junior Consultant, Dept of Neurology, Dhaka Medical College Hospital

5. Senior Consultant (Medicine), Nilphamari Sadar Hospital, Nilphamari

6. Professor of Neurology, Bangabandhu Sheikh Mujib Medical University

7. Professor of Neurology, Dhaka Medical College Hospital

8. Professor and Director, National Institute of Neurosciences and Hospital, Dhaka 
Nerve conduction studies (NCS) have been carried out by several investigators in chronically exposed industrial workers with raised blood lead concentrations to see the electrophysiological evidence of neuropathy ${ }^{5-9}$. Interestingly enough, electrophysiology was found to be normal in many of these patients, who had minimally slowed motor conduction with slightly reduced compound muscle action potentials. These minimal abnormalities tended to improve once lead exposure ceased. Abnormalities of sensory nerve action potentials were noted only in a few of these subjects ${ }^{9}$. There is a generally weak relationship between the development of lead neuropathy and blood lead levels, at least for the subacute motor neuropathy, leading to speculation that the metabolic basis for the neuropathy is interference with porphyrin metabolism $^{10}$. So we wanted to investigate the relationship between polyneuropathy and serum lead level among Bangladeshi patients.

\section{Methods:}

This hospital-based case- control study was carried out in the department of Neurology, Bangabandhu Sheikh Mujib Medical University, Dhaka in collaboration with Bangladesh Atomic Energy Centre, Dhaka from July 2001 to June 2002. A total number of 120 polyneuropathy patients were selected during the study period. Out of them 46 patients fulfilling the inclusion criteria were finally selected as cases. The controls (46) were selected randomly who were non-polyneuropathy patient. The diagnosis was confirmed by a senior neurologist and nerve conduction study was done. Written informed consent was taken from all patients. Each of them was screened for possible common etiologies. Past medical history, family history, drug history, occupational history of exposure of lead and detailed clinical examination including examination of nervous system and cardiovascular system was done. The following investigations were done routine blood examination, urine R/E, X-ray chest, random and fasting blood sugar, ECG, blood urea, serum creatinine, serum electrolytes. The lead concentration in the blood were detected by X-ray fluorescence (XRF) technique on both case and control groups. Nerve conduction study and CSF examination were done among the cases. All relevant information from history, clinical findings and investigation results were documented in predesigned interview schedule and check list. Recorded data were compiled and possible statistical analysis was done. The study protocol was approved by the institutional ethical committee.

Inclusion criteria:

- Typical history of polyneuropathy and fulfilling the lead induced neuropathy diagnostic criteria

- Age between 6-60 years

- Patient with positive nerve conduction study consistent with polyneuropathy

- CSF findings consistent with polyneuropathy

\section{Exclusion criteria:}

- Debilitated patient

- Patient with intercurrent illness

- Patient with diabetes mellitus, thyroid dysfunction, kidney dialysis and alcoholic polyneuropathies

- Occupational H/O exposure of lead.

\section{Consent to participate:}

Informed written consent was obtained from each of the respondent after appropriate explanation of the study procedure.

\section{Consent to publish data:}

The manuscript does not contain any individual image, video or any detail of individual patient, the publication of which might be subjected to prior consent to publish the data

\section{Ethical approval:}

Ethical permission was granted by the ethical review committee of Dhaka Medical College (DMC) after proper submission of the study protocol.

\section{Result:}

Total 92 respondents were studied, among them 46 were cases and 46 were controls. Mean age of the cases and controls were $30.87+14.53$ years and $30.91+12.03$ years respectively. Of the total respondents, $89.1 \%$ were male and $10.9 \%$ were female (Table-1). Among the cases, more than half of the respondents (55\%) were in sub acute type of polyneuropathy, followed by acute $(30 \%)$ and chronic 
(15\%) type of polyneuropathy (Fig.1). The mean CSF sugar level among the cases was $4.8191+2.7442$ $\mathrm{mmol} / \mathrm{L}$ and mean CSF protein level was $112.00+$ $65.04 \mathrm{gm} / \mathrm{L}$. The mean CSF protein was higher in acute polyneuropathy than in subacute and chronic cases, which was also statistically significant $(p<.001)$ (Table-2). The mean blood lead level among cases was 45.5587 with a standard deviation of +35.2625 and among control were 33.2065 with a standard deviation of +5.6793 . The difference was statistically significant $(p=0.021)$ with a higher blood lead level among the cases (Table-3).

\section{Table-I}

Demographic characteristics of the respondents

\begin{tabular}{lccc}
\hline Characteristics & Group & Case & Control \\
\hline Age in year & $30.83+14.83$ & $30.91+12.03$ & \\
$($ Mean +SD) & & & \\
Sex & Male & $41(89.1 \%)$ & $5(10.9 \%)$ \\
& Female & $41(89.1 \%)$ & $5(10.9 \%)$ \\
\hline
\end{tabular}

Figure 1 showing the majority (55\%) of the cases had sub acute polyneuropathy, followed by acute $(30 \%)$ and chronic $(15 \%)$ polyneuropathy.
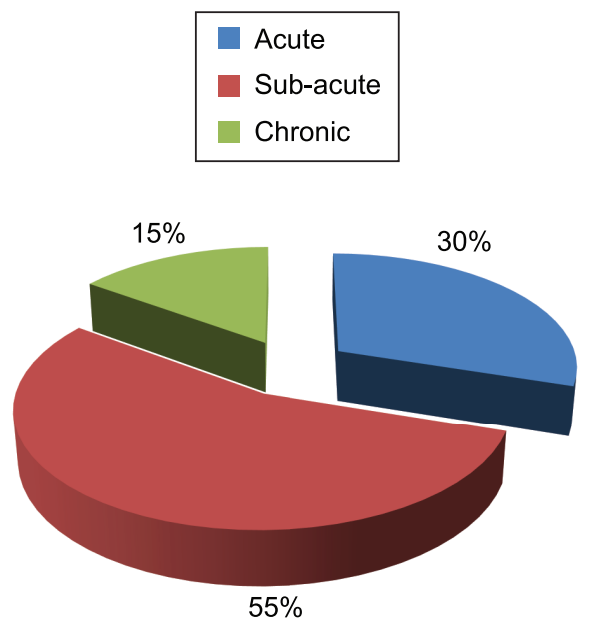

Fig.-1: Distribution of the cases by types of polyneuropathy

Table-II

Distribution of the cases by biochemical analysis of CSF

\begin{tabular}{lccccc}
\hline CSF sugar(mmol/l) & No. & Mean $(\mathrm{mmol} / \mathrm{l})$ & $\mathrm{SD}(\mathrm{mmol} / \mathrm{l})$ & $\mathrm{F}$ & Sig. \\
\hline Acute & 14 & 6.1886 & 3.97 & 2.916 & .065 \\
Sub-acute & 25 & 4.0656 & 1.76 & & \\
Chronic & 07 & 4.7714 & 1.74 & & \\
CSF protein(gm/l) & & & & & \\
Acute & 14 & 170.8571 & 30.59 & 15.997 & .000 \\
Sub-acute & 25 & 96.28 & 63.56 & & \\
Chronic & 07 & 50.4286 & 1.61 & & \\
\hline
\end{tabular}

Table-III

Lead level in blood among cases and controls

\begin{tabular}{lccccccc}
\hline Characteristic & Respondents & No. & Mean & SD & $t$ & df & $\mathrm{p}$ \\
\hline Blood level of lead & Case & 46 & 45.5587 & 35.2625 & 2.346 & 90 & .021 \\
$(\mu \mathrm{gm} / \mathrm{dl})$ & control & 46 & 33.2065 & 5.6793 & & & \\
\hline
\end{tabular}




\section{Discussion:}

Lead, being an ubiquitous and versatile metal, has become widely distributed and mobilized in the environment and with a consequent increase in human exposure. Exposure of human populations to environmental lead has increased with industrialization and large-scale mining ${ }^{11}$. Global lead contamination, of lead in soil, water and air is attributable to increased of human activities ${ }^{12}$. The pre-industrial blood lead level in humans was estimated to be about $0.016 \mathrm{mg} / \mathrm{dl}$, which is 50 200 times lower than the lowest reported levels in human today. ${ }^{13}$. The matter of huge concern is that this level is about 625 times lower than the current level of concern for children (i.e. $10 \mathrm{mg} / \mathrm{dl}$ ) proposed by the Centers for Disease Control and Prevention in the USA ${ }^{14}$.

In this study, majority of our cases had sub acute form of polyneurpathy along with higher CSF protein level in comparison to the age and sex match control. The mean serum lead level was also higher among the cases.

Age of the respondents was found to have no relation among the groups but younger the age, more would be the susceptibility to develop polyneuropathy. Brody DJ et al also showed similar findings ${ }^{15}$. But Reinhard K et al ${ }^{16}$ showed that lead concentration was found to be increasing with age. One possible reason for this discrepancy might be that they had been residing close to high lead exposure, like highway or busy traffic. But our study had age matched in between cases and control. So the effect of increasing age, if any, is minimal. Most of the previous electrophysiological studies have concentrated on groups of workers exposed to lead with or without neuropathic symptoms, or on those occasional patients with subacute motor weakness associated with lead toxicity. Minor changes in distal motor nerve conduction or CMAP amplitudes have been noted when the level of safe chronic occupational exposure was exceeded ${ }^{3,5-7}$. But the uniqueness in our study is that we excluded the definite occupational exposure of lead among respondents.

The nervous system is the most sensitive and chief target for lead related toxicity. Both the central and the peripheral nervous system may be affected ${ }^{17}$. The effect also depends on age of exposure of the patient and the duration. The effects on the peripheral nervous system are more pronounced in adults while the central nervous system is the target in children ${ }^{18}$. The earliest lead-induced changes are observed in the endothelium of the microvasculature, which is an essential component of the blood-brain barrier ${ }^{19}$. Electrophysiological studies showed that neurosensory processing may be affected by lead and provided a direct link between lead exposure and neurologic deficits ${ }^{20}$.

In this study, the mean blood lead level was significantly higher in neuropathic respondents. This finding was supported by $\mathrm{O}$ Rubens et al, and Ruth Lilis et $\mathrm{al}^{21,22}$. Though these studies had some difference in methodology than this one, the result was comparable. This is probably attributed to recent industrial development in Bangladesh. Our finding about blood level also supports the conclusion World Health Organization (WHO) have made in a theme paper about environmental lead exposure and public health concern, mentioning that rapid industrialization and the persistence of lead in the environment, exposure is likely to remain a significant public health problem in most developing countries for many years ${ }^{23}$.

\section{Limitations:}

Non-uniform nerve conduction velocity study was carried out in all respondents to detect particular nerve conduction velocity in the case group only. Again different nerves were tested in different respondents. Although X-Ray Fluorescence spectrometry is a powerful tool for elemental analysis, it cannot trace out the actual normal limit of lead level in blood.

\section{Conclusion:}

This study finding showed that increase blood level of lead was associated with polyneuropathy. Additional in depth research is needed to determine the causal factors of polyneuropathy.

Conflict of interest: None

\section{References:}

1. Kalia K, Flora SJ. Strategies for safe and effective therapeutic measures for chronic 
arsenic and lead poisoning. J Occup Health, 47: 1-21, (2005).

2. Cullen MR, Robins JM, Eskenazi B. Adult inorganic lead intoxication: presentation of 31 new cases and a review of recent advances in the literature. Medicine 1983;62:221-47.

3. WindebankAJ. Metal neuropathy. In: Dyck PJ, Thomas PK, Griffin JW, et al, eds. Peripheral neuropathy. 3rd ed. Philadelphia: WB Sanders, 1993:1549-70.

4. Saryan LA, Zenz C. Lead and its compounds. In: Zenz C, ed. Occupational medicine. 3rd ed. Mosby-Year Book. St Louis: CV Mosby, 1994:506-41.

5. Araki S, Honma T, Yanagihara S, et al. Recovery of slowed nerve conduction velosity in lead-exposed workers. Int Arch Occup Environ Health 1980;46:151-7.

6. Seppäläinen AM, Hernberg S. Sensitive technique for detecting subclinical lead neuropathy. Br J Ind Med 1972;29:443-9.

7. Seppäläinen AM, Tola $S$, Hernberg $S$, et al. Subclinical neuropathy at "safe" levels of lead exposure. Arch Environ Health 1975;30:1803.

8. Catton MJ, Harrison MJG, Fullerton PM, et al. Subclinical neuropathy in lead workers. BMJ 1970;ii:80-2.

9. Buchthal F, Behse F. Electrophysiology and nerve biopsy in men exposed to lead. $\mathrm{Br} \mathrm{J}$ Ind Med 1979;36:135-47.

10. Thomson RM, Parry GJ. Neuropathies associated with excessive exposure to lead. Muscle Nerve 2006; 33 (6): 732-41.

11. Flegal AR, Smith DR. Current needs for increased accuracy and precision in measurements of low levels of lead in blood. Environmental Research, 1992, 58: 125-133.

12. Nriagu JO, Pacnya JM. Quantitative assessment of worldwide contamination of air, water and soils by trace metals. Nature, 1988, 333: 134-139.

13. Flegal AR, Smith DR. Lead levels in preindustrial humans. New England Journal of Medicine, 1992, 326: 1293-1294.
14. Preventing lead poisoning in young children: a statement by the Centers for Disease Control and Prevention. Atlanta, GA, Centers for Disease Control and Prevention, 1991.

15. Brody DJ et al. Blood Lead level in the U.S. population: phase 1 of the Third National health and Nutrition Examination Survey (NHANES III, 1988-1991) JAMA 1994; 172:277-83.

16. Reinhard K, Alden K, Henderson W, Randoloph $D$, Mary N, Manzurul $\mathrm{H}$, et al Blood Lead level of primary school children in Dhaka, Bangladesh; Environmental health Prospectives 2001; 109(6):563-66.

17. Cory-Slechta DA. Legacy of lead exposure: consequences for the central nervous system. Otolaryngol Head Neck Surg 1996; 114: 224 226.

18. Brent JA. Review of Medical Toxicology. Clin Toxicol 2006; 44: 355-355.

19. Ranson SW, Clark SL, in: Saunders WB (Ed). The Anatomy of the Nervous System, 10th edn., Chap. III, Philadelphia 1959; pp. 71-88.

20. Goldstein GW, Developmental neurobiology of lead toxicity, in: Needlmann HL. (Ed), Human Lead Exposure, CRC Press 1992; Boca Raton, FL, pp. 191-208Rubens O, Logima I, Kravale I, Eglite M, Donaghy M. Peripheral neuropathy in chronic occupational inorganic lead exposure: a clinical and electrophysiological study. J Neural Neurosurgery Psychiatry 2001; 71:200-4.

21. Rubens O, Logima I, Kravale I, Eglite M, Donaghy M. Peripheral neuropathy in chronic occupational inorganic lead exposure: a clinical and electrophysiological study. J Neural Neurosurgery Psychiatry 2001; 71:200-4.

22. Ruth L, Alf F, Josef E, William EB, Sidney D, Henry AA, WilliamR et al. Prevalence of Lead disease among secondary Lead smelter workers and biological indicators of lead exposure. Environmental research 1977; 14:255-85.

23. Shilu T, Yasmin EVS, Tippawan P. Environmental lead exposure: a public health problem of global dimensions. Bulletin of the World Health Organization, 2000, 78 (9). 